\title{
Analysis of Use of Virtual Reality Technologies in History Education: A Case Study
}

\author{
Gürkan YILDIRIM ${ }^{\star}$ \\ Mehmet ELBAN ${ }^{2}$ (D) \\ Serkan YILDIRIM ${ }^{3}$ \\ ${ }^{1,2}$ Bayburt University, Bayburt, Turkey \\ Email:gvildirim@bayburt.edu.t. \\ Email:mehmetelban@bayburt.edu.tr \\ Atatürk University, Erzurum, Turkey \\ ${ }^{3}$ Email:serkanvildirim@atauni.edu.tr
}

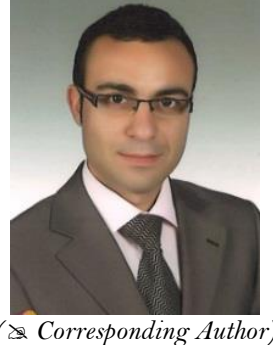

\begin{abstract}
Today, many innovations have been experienced in technology. These innovations progressively take their places in education environments. Virtual reality environments are among activity areas that have been frequently discussed and used in education environments in the recent years. In this context, this study aimed to determine general opinions of undergraduate students who were included to study scope about virtual reality technologies, and privately, to determine the students' opinions about use of virtual reality glasses in history education and to determine their suggestions in this subject. Case study method was preferred in this study. Sampling was created as selecting 25 undergraduate students according to the study purpose. Data was collected with interview technic and analyzed with content analysis method. According to study results, it was concluded that virtual reality implementations were liked by participants. Additionally, participants stated that use of the current technology in course activities would be beneficial. It was thought that especially the feelings of reality and being present in the location, which were caused by virtual reality implementations, were among the factors that affected participants and increased their interest in the course. Moreover, virtual reality implementations were thought to be technologies that could enable the individuals, especially those with disabilities or had different inadequacies (i.e. financial, time etc.), to actively involve in learning processes. Similarly, virtual reality technology was thought to contribute, at least partially, equal opportunities concept in education.
\end{abstract}

Keywords: Virtual reality, History education, Virtual reality simulation, Training.

Citation | Gürkan YILDIRIM; Mehmet ELBAN; Serkan YILDIRIM (2018). Analysis of Use of Virtual Reality Technologies in History Education: A Case Study. Asian Journal of Education and Training, 4(2): 62-69.

History:

Received: 23 January 2018

Revised: 6 February 9018

Accepted: 12 February 2018

Published 15 February 2018

Licensed: This work is licensed under a Creative Commons Attribution 3.0 License $(\mathrm{cc})$

Publisher:Asian Online Journal Publishing Group
Contribution/Acknowledgement: All authors contributed to the conception and design of the study.

Funding: This study received no specific financial support

Competing Interests: The authors declare that they have no conflict of interests.

Transparency: The authors confirm that the manuscript is an honest, accurate, and transparent account of the study was reported; that no vital ace study as planned have been explained.

Ethical: This study follows all ethical practices during writing.

\section{Contents}

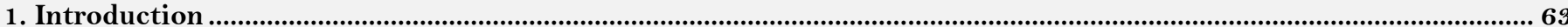

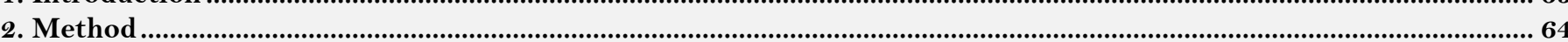

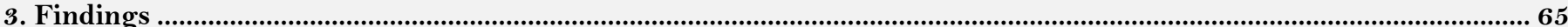

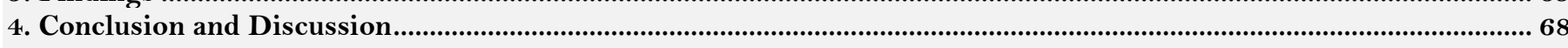

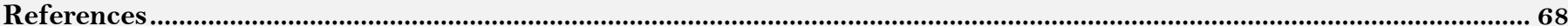




\section{Introduction}

Education is generally defined as the formation of permanent behavioral change in an individual's behaviors through his own experiences (Ertürk, 1972). Learning is a cognitive process as requires individual's active participation (Fer, 2011). According to another approach, learning is a process in which each individual constructs himself (Fer, 2011). From this point of view for education and teaching, it is seen that the changes for which the individual actively involves in learning processes are targeted in individuals' behaviors, knowledge and approaches. Technological changes bring many implementations that are convenient to this definition and will create opportunities for individuals to learn efficiently and permanently.

In the analysis of the current technologies developed today, it is seen that virtual reality (VR) implementation versions for education based use have been one of the frequently discussed technologies in the recent years. Therefore, VR implementations have been, indeed, discussed for many years and are among the technologies that are developed for various purposes. In a time-based analysis, VR studies were brought forward after 1950s (Başaran, 2010). Ever since, many studies have been conducted in VR area and the current technology has constantly been developed.

The concepts of VR and augmented reality are frequently confused with each other. Although augmented reality implementations are considered as a part of VR, it includes some differences. Augmented reality happens by placing virtual objects in real environments (Azuma, 1997). However VR can be defined as implementations by which individuals find themselves in a virtually created environment using various tools and interact with the environment (Çavaş et al., 2004; Carrozzino and Bergamasco, 2010). As also Rheingold (1991) stated, VR could be defined as experiences which individuals could walk around in three dimensional environments, developed with computer technologies, and the environment could be observed from all angles. Generally, according to VR implementation definitions, the feelings that individuals directly interact with the environment and feel themselves in the related environment are emphasized.

Today, VR implementations have continued their presence in many areas from tourism to education. VR implementations could be possibly encountered in a touristic destination advertising, historical elements presentation or in entertainment sector. Besides this wide range of use areas, developing and spreading of the current technology enable the increase use of VR implementations in education environments. Çavaş et al. (2004) classified use of VR in education environments and Başaran (2010) classified use of VR implementations in all areas. A combination of these two classifications was summarized in Graph-1.

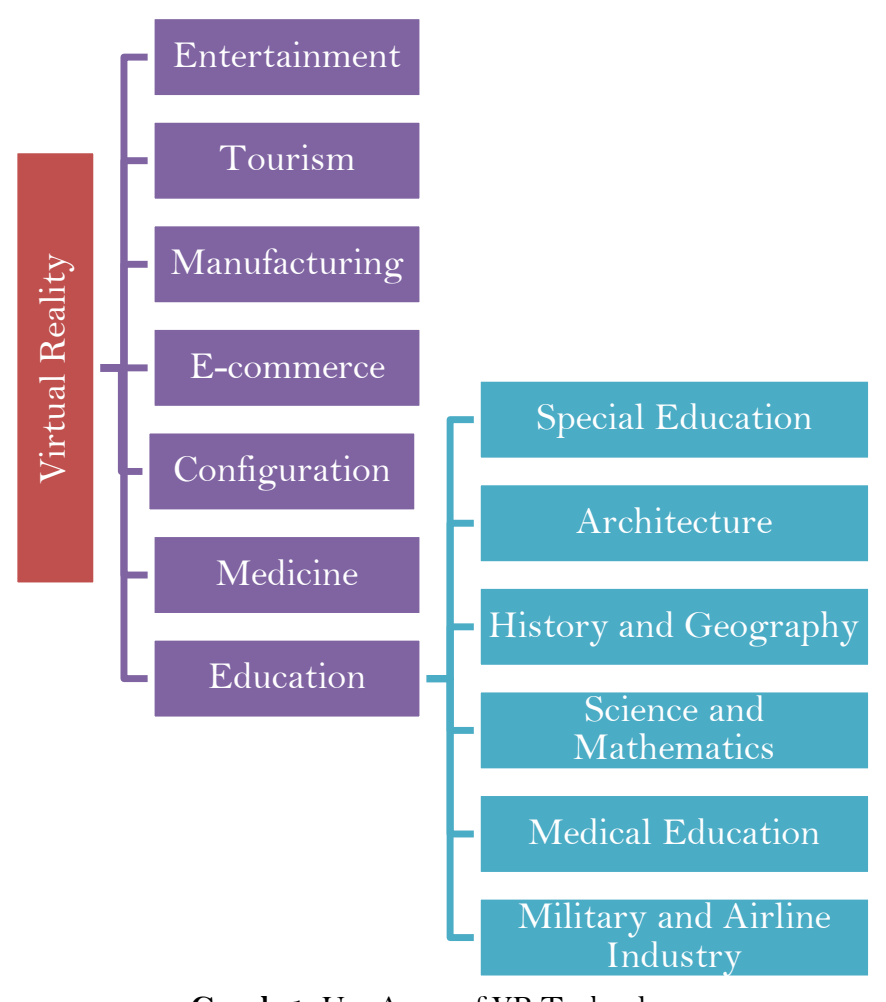

Graph-1. Use Areas of VR Technology

It could be said that there are many positive aspects of VR implementations, which have wide range of use area, mentioned in literature. Use of VR in education has increased with a parallel development of computer-aided education. Use of VR in education can be traced back to 1989 (Pantelidis, 2010). VR implementations enable individuals to regard themselves as a part of the environment while increasing their interest in the related course (Nooriafshar et al., 2004; Başaran, 2010). Moreover, use of VR technologies facilitates especially showing events which are difficult to observe, organizing dangerous activities and making expensive applications in classrooms (Nooriafshar et al., 2004). Additionally, VR technology using teaching materials are expected to facilitate learning. Many learning outcomes can be obtained with teaching materials, which are prepared based on VR technology, including students visualize abstract concepts, observe atomic or astronomic events, interact with events, make excursions and experience unsecure environments in a secure manner. The number of these examples can be easily increased. Eventually, it is widely accepted that VR technology can support education (Youngblut, 1998).

In the view of the stated positive aspects of VR applications, use of this technology is thought to be effective in history education, either. Generally, it is seen that many new implementations have been used in history education with parallel to technological developments. Textbooks had been considered as the primary teaching material in history education in both Europe and our country until 2000s (Stradling, 2003). However, today, the importance of 
information and communication technologies in education has increased (Adesote and Fatoki, 2013). In this direction, different methods and technics are started to be used in history education.

In a general view, as a scientific discipline, history has suitable conditions enabling it to benefit from technology in education process. In this context, use of VR in history education should not be regarded as a new approach. For example, studies which are made with VR and stereoscopic projections have existed (Neamtu et al., 2012). Therefore, VR glasses are among the materials that can be utilized in history education. Hence, without depending on history textbooks, historical locations can be visually visited to observe their structure, characteristics and versions in the past and students can behave freely in those locations (Schweizer, 2014). From this point of view, VR technologies present a real world perception for historical past. In this context, history educators are suggested to have interest in these technologies and increase their knowledge about VR technologies (Allison, 2008). Hence, more effective study environments can be created in history education.

Rapid technological developments and use of these technologies in education environments require constant research of different technologies and analysis of educational aspects. Especially, VR glasses locate users in a visual world with low cost and enable interaction with environment using its own technologies or with additional technologies. In this context, analysis of effects of VR glasses that have had a large market share in the recent years on education is important. In the scope of this study, it was intended to determine undergraduate students' opinions toward virtual reality technologies and privately to determine their opinions toward use of virtual reality glasses in history education and their suggestions about this subject. According to study purpose, the answers of the below stated research questions were researched:

1. What are the opinions of participants toward use of VR glasses?

2. What are the opinions of participants toward the differences of use of multiple environment contents provided with VR glasses and use of the materials, i.e. video and images, provided in traditional learning processes?

3. What are the opinions of participants toward the content provided in VR environment for the course History of Civilizations?

4. What are the opinions of participants toward use of VR glasses in history education?

\section{Method}

In the scope of this study in which use of VR technologies have been analyzed, case study method was used as one of the qualitative research methods. Determining general opinions of participants and need to analyze the reasons behind these opinions in detail shaped the method selection. It is stated in literature that people from a group with whom information can be obtained can be included to research instead of including all participants in order to collect detailed information in the researchers conducted with case study (Büyüköztürk et al., 2010).

\subsection{Study Group}

In the scope of this study, 12 male and 13 female, totally 25 participants, who were freshmen in Primary School Teaching department and attended the course "History of Civilizations" in Bayburt University, were included into this research. Although all of them were aware of VR technologies, very few of them stated that they had previously used the current technology.

\subsection{Implementation Process}

A pilot study was organized in implementation process and, in order to enable participants to adapt the learning environment, a VR glass use activity was organized with a nearly 5-minute learning content that was not previously seen by participants and would not be used in study scope. In order to create VR glass using experience and ability to interact with the content, flexible studying opportunities were given to participants and time limitations were not set, moreover necessary technology use training was provided for them to interact with the environment in this process. Additionally, $360^{\circ}$ rotating chairs were used to increase participants' experiences of preferring axis and them to be able to move every sides easily in a limited physical location and them to be able to use movement abilities of the virtual reality glasses completely. Besides, use of VR glasses that participants could change directions depending on their head moves and had internal movement buttons on itself to facilitate the control was preferred. Therefore, it was ensured them to adapt the environment, learn the how to use the glasses and adapt the new technology that they never used before. After all of the participants experienced content usage with VR glasses and felt ready, research processes started.

In research process, an additional content that included audio and visual elements to introduce Kaaba related to Islam History education was presented. In this content, participants were able to obtain audio information as interacting with information points as they could walk around Kaaba. In this content that was designed in a form without any time limitations, participants were able to make learning interactions as much as they wished. Any time limitations were not applied to participants during study process as they were able to establish learning process by themselves. Interviews were organized with the participants who completed learning activity and data collection process started.

\subsection{Data Collection}

Interview technic was used in this research as a data collection technic. In this purpose, semi-structured interview form was prepared by researchers. Semi-structured interview form was consisted of 6 open-ended questions. In order to ensure validity of the interview form, opinions of 3 experts were obtained and the final version of the interview form was created with Turkish language experts' controls. At the end of the implementation, researchers conducted interview process. Interviews were organized depending on voluntary basis and interviews were recorded with an audio recording device. 


\subsection{Data Analysis}

In data analysis process, content analysis method was used. The answers in audio recording device in which participants' answers to research questions were stored were deciphered. The deciphered text contents were analytically described as creating themes and analysis units in framework of research problems. In order to sustain coding security during these processes, researchers worked on the same interview records. Coding security ensures that different coders code the same text or message accordingly or reach the same results in different times (Bilgin, 1999). At the end of the analysis process code, category and theme structures were created and relational structures were obtained.

\section{Findings}

In the scope of this research which aimed to determine undergraduate students' opinions toward VR technologies and, privately, to determine their opinions toward use of VR glasses in history education and their use suggestions, below stated findings were obtained as a result of the organized interviews.

In the study scope, interviews were made with 25 participants and $76 \%$ of them stated that they never used VR glasses before this case study and $24 \%$ of them stated that they used this technology at least once. However those, who never used VR glasses before, stated that they were aware of this technology.

\subsection{What are the Opinions of Participants toward Use of VR Glasses?}

In the analysis of general opinions of participants toward VR glasses and the contents that were provided with these glasses, all of the participants $(100 \%)$ that included to the study stated that they liked this technology very much. However, two of the participants who shared positive opinions emphasized that contents might have been prepared more interesting and immersive, while one participant emphasized that the technology was good however it was worrying for new starters. Participants' opinions about their likings were presented in Table-1.

Table-1. General opinions toward use of VR glasses

\begin{tabular}{l|l}
\hline General Opinions & F \\
\hline Realist environment & 13 \\
\hline Feeling of being present in the environment & 13 \\
\hline Access to destination that is difficult to visit & 11 \\
\hline Providing concrete learning environment & 7 \\
\hline Interesting environment & 1 \\
\hline Source: From data collected &
\end{tabular}

According to findings, participants emphasized that they found the contents that were provided with VR glasses as realistic. Besides, participants stated that they felt a part of the environment that was provided to them and had a feeling of being present in the exact location. Additionally, participants stated that the destinations, where they could not go or could not find an opportunity to be in, could be easily visited with this technology. These findings especially emphasizes that VR technologies can be very useful for people, especially those with walking disabilities, elder people or people with financial difficulties. Additionally, some of the participants stated that the contents that were provided with VR glasses presented concrete learning environment. In this direction, example participants' opinions toward use of VR glasses could be listed as follows;

P_1: You live in the location, it is very useful for someone who cannot go there by himself. I directly remembered my mother by watching, she has fear of flying and I think to have her watched something like this one, I mean, I felt as if I was there for a moment...

P_6: I found it very useful. It is a big advantage for students who have visual intelligence because you live as if being present within that moment so that very memorable and quite practical.

P_8: ... bringing a child in a village to Çanakkale or providing him to visit those places is very difficult and Ministry of National Education might cause some problems with this for example maybe an accident in the road can happen, we can have children visited those places as preparing a Çanakkale video and they can have the same excitement. They can have similar excitement if not the same

P_9: Positive aspects are if a person who likes to visit a lot of destinations goes to the places by himself, it can be more expensive but in this way he can see the locations with videos.

$P_{-}$13: It is better than never although it does not provide a whole presence feeling, it contributed a lot, it is very good for disabled and elder people because it makes you feel like walking and being present in there for example if we present this to an elder person who could not go to Mecca, I think, it can be very good...

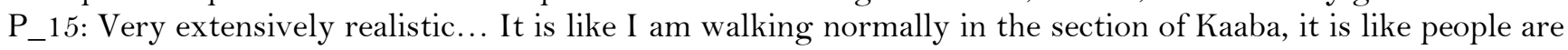
real.

P_21: It was very good. As learning by experience principle in education, I think, this can be very good in education. I felt like I went there while using this glass. ... Indeed, it created very different emotions in me.

For example I was scared very much in some sections I found it that much realistic.

In addition to positive opinions of participants toward VR environments, that were also some drawbacks. One of the participants stated that VR environments could be more useful if they were more realistic. Besides, another participant stated that contents and the current technology did not draw the participant's interest. In this content, example participants' opinions could be listed as follows;

P_14: It was, indeed, good but the contents could be developed more.

$P_{-}$15: It can harm us in some cases. ... The only thing that I can say as a negative comment ... effects etc. Had better be more realistic.

P_23: It was, indeed, good. But generally this kind of technologies do not draw my interest.

P_25: It was good. I do not know, maybe, it is because I used it the first time but I found it scary. 
3.2. What are the Opinions of Participants toward the Differences of Use of Multiple Environment Contents Provided with VR Glasses and Use of the Materials, I.E. Video and Images, Provided in Traditional Learning Processes?

During the interviews conducted with participants, they were asked to compare the multiple environment contents that were normally used in lectures such as images and video with the contents that were provided with VR glasses. All of the participants $(\mathrm{N}=25)$ that were included to the research stated that VR contents were more effective compared to multiple environment contents that were presented in classrooms. Only one participant stated that VR technologies were more effective however they could create various inconveniences in long terms uses. In this context, participants' opinions toward comparison between VR based learning contents and traditional multiple environment components were presented in Table-2.

Table-2. Comparison of multiple environment components and VR technology based learning contents that are used in learning environments

\begin{tabular}{l|l}
\hline Superior aspects of VR environments & F \\
\hline Providing for permanent learning environments & 13 \\
\hline Facilitating the learning & 8 \\
\hline Providing for enjoyable learning environments & 7 \\
\hline Interesting contents & 5 \\
\hline Supporting the individual learning & 3 \\
\hline Providing for active learning & 1 \\
\hline Difficulty of long term use & 1 \\
\hline Source: From data collected &
\end{tabular}

In the view of findings, it was determined that the contents provided with VR glasses increased the permanent learning. Besides, this technology facilitated the learning and provided for enjoyable learning environments were among the emphasized points. Additionally, participants also stated that the contents were more interesting than multiple environment contents and supported individual learning and active learning. Example participants' opinions toward the content comparison could be listed as follows;

P_2: Its difference from other environments is that it is more convincing. For example is seeing a photo or

living more permanent? Therefore I believe that it will facilitate learning more.

P_5: So different compared to picture and video. ... Our attention can be lost quickly but here, there is not such possibility because you are in it, you totally live, therefore, they (image and video) last short time and can stay in our short term memory.

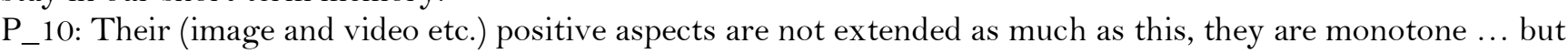
this is more realistic and three dimensional. Additionally, you live in a moment, if this feeling can be brought in lectures as interesting, for example, if the whole education program is revised with this, it can be more interesting.

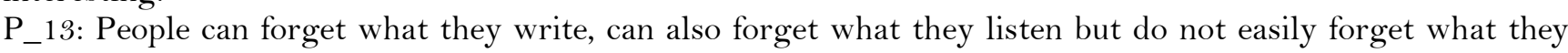
live. This is indeed a kind of living. We listen a lecture after a certain time, our brain could not handle everything, it will be forgotten if we write it will kind of live longer, picture; it will become visual intelligence. But if it is in a way of virtual reality, it can address all kinds of intelligence types, because it is audio, picture and revival, it can become permanent.

$P_{-} 14:$... with this glass, like you are there, like you live. I mean, it gives the feeling of totally being present in there. But in others, such as a normal video, I cannot have that feeling. For example while looking at a photograph, you merely look, it is consisted of a single unit but you cannot be in the location. At the same time it increases permanency in learning.

P_18: For example, if we compare the slideshows that we use in our lectures, with this technology, for example, there can be videos in that slide and we watch them together but it will happen individually with this technology and I think it is better being individually for us, it can be easier to totally focus on a subject. I think learning with this technology will be more enjoyable.

P_22: For example, when our teacher shows us a video or something in slideshows during lectures, that time we can think of something else but when we use this technology, even though, we think of something else, it will ensure that we focus on this subject. Or it will be interesting for someone who is not interested in the course because one enjoys so much while using this technology.

P_25: This technology can be used during lectures but, as I said, it should not be used for long term. It affected me negatively, I do not know, maybe that is why I used it for the first time. For sure if we have lectures with these virtual reality glasses, it can be more effective than multiple environment components.

\subsection{What are the Opinions of Participants toward the Content Provided in VR Environment for the Course History of Civilizations?}

In the study scope, participants were asked to state their opinions toward showing of one of the subjects mentioned in History of Civilizations with VR implementation. In this context, participants' general opinions were presented in Table-3.

Table-3. Participant Opinions toward the Effect of VR based Content

\begin{tabular}{l|l}
\hline Opinions toward the content & f \\
\hline Feeling of being present in the environment & 19 \\
\hline Desire to go (exciting) & 9 \\
\hline Realistic environment & 9 \\
\hline
\end{tabular}

Source: From data collected 
In the view of findings, participants stated that they felt as if they were present in the environment thanks to the provided content and VR technology. It was emphasized that the audio content that was provided with the content was very effective in this condition (f:6). Besides, it was stated that the content created excitement in participants therefore the desire was created for going to the created environment in real life. Additionally, the provided content was described as very realistic by some of the participants. In this context, example participants' opinions could be listed as follows;

P_6: ... frankly, I liked it so much. It gave me a feeling like I was really there. Azan reciting in the background supported this feeling well. I felt as if I was in the location and I was really there.

$P_{-}$12: I felt like I was there for a moment. I wanted to go there in real. I told myself I wished I had been there. That desire occurred to me.

P_14: I found it so real, I was walking, looking around. Actually I was sitting down that time, I knew it, but still it gave me excitement. It influenced me so much.

P_16: In that section, my heartbeats fastened. It made me excited, because, I could not go there. I mean, seeing the location with virtual reality glasses was so special for me if I will not be able to go in real life.

P_24: I wanted to go there so much. I felt like I went there, walked around and turned around, it was so real.

In the study scope, participants mentioned that some improvements could be applied to the provided content. In this context, they stated that the visual elements provided in the structures in the content that was provided with VR glass should be designed better $(\mathrm{N}: 2)$. Additionally, it was also suggested that use of real visuals could be more effective rather than using animation visuals (N:2). Example participants' opinions toward improvement of the content could be listed as follows;

P_1: ... but structures were a bit bad.

$P_{-}$11: The only flaw that I thought was that it was animation it could have made me engage more.

P_13: Reality of architectural structure might have been better. For me, architectural structure might have been more realistic and precise.

\subsection{What are the Opinions of Participants toward Use of VR Glasses in History Education?}

In the study scope, participants were asked to state their opinions toward use of VR technologies in history education. In this context, all of the participants $(\mathrm{N}=25)$ stated that they would like to use VR technologies in history courses and use of these technologies would be helpful. It was stated that lecturing method like this would make courses more enjoyable. Additionally, participants were asked to state in which conditions they would prefer VR technologies in especially history course. In this context, their opinions toward these conditions were presented in Table-4.

Table-1. Participants' Opinions toward Use of VR Technologies in History Education

\begin{tabular}{l|l}
\hline Suggestions for use of VR Technologies in History Education & F \\
\hline Visualizing historical events & 17 \\
\hline Showing museums, temples etc. & 8 \\
\hline Source: From data collected
\end{tabular}

Source: From data collected

In the view of findings, participants emphasized effectiveness of VR technologies to show important historical events (i.e. wars, treaties etc.). In this context, it was thought that participants made such recommendations due to their willingness to live that moment in particularly. Additionally, they also emphasized their desire to benefit from superior aspects of VR technologies in showing historical locations (i.e. museums and temples etc.) that they could not find opportunities to go and visit. Additionally, it was also stated that history courses might be more enjoyable as VR technologies removed their negative biases toward history courses.

$P_{-}$1: For example, while learning a war or a treaty, if you also sit down, be present in that table or be in the war, those dialogues, for example, if you listen the words of Atatürk in a war, I think it can be more effective.

P_4: Let's think about War of Çanakkale, for example, let's think about a student watching war scene at the background, I think it can be more memorable, while even seeing the locations, where wars were made on, I think, this can be more effective.

P_8: For example, Egyptian Pyramids are in one of the Seven Wonders of the World but how much opportunity do we have to go and see those, not much ... but if Ancient Pyramids are shown with VR technologies, I can visit those places. OK, the same feeling cannot be given but still I can learn many things. At least I can learn information in the show.

P_13: Let's say we learn İstanbul, Ottoman Empire's capital city, we learn a subject related to palaces, if the lecture is designed as in a museum atmosphere in those palaces and an audio is placed in the background, it can be as if we both listen the lecture and visit those places and it can be more memorable. For example, if you are like watching an archeological excavation and being present next to that, it can be memorable. Because it addresses to verbal intelligence more, it is more difficult to understand but in this way, it can be more memorable.

P_24: ... It can be better in terms of permanency ... we can watch people of the first ages with this technology, it can be more interesting and provide a better learning environment. One of the positive aspects of use of this technology in history education is, I think, history course is generally known as a boring course by many people but, thanks to this technology many people's interest to history course can increase.

In a summary of participants' opinions toward use of VR technologies in history education, the current technology was emphasized as follows;

- It could remove the boring aspects of the course as eliminating monotone lecturing methods,

- It could increase permanency,

- I could increase interest and motivation toward the course, and

- It could provide opportunity for learning as doing-living. 


\section{Conclusion and Discussion}

Data obtained from participants in this research which aimed to determine undergraduate students' opinions toward VR technologies and, privately, to determine their opinions toward use of VR glasses in history education and their suggestions in this subject, below stated findings were obtained as a result of the organized interviews was analyzed and results were presented as in the order of research questions.

It could be said that liking levels of participants toward VR environments whose use was relatively new in learning environments were high. Participants regarded the provided contents as realistic and gave participants the feeling of being present in the related environment and these conditions helped formation of this liking level. This condition could be interpreted as participants would like to feel themselves as a part of the provided content and felt more comfortable in the created environment. Similarly, Hussein and Nätterdal (2015) stated that VR based environments created an exciting and immersive experience for users and they regarded themselves as a part of the environments. After watching the provided contents, participants stated that VR environments could be very useful for individuals, especially those with disabilities and had some kinds of difficulties (i.e. age, financial difficulties etc.) to have an excursion experience. Similarly McLellan (1996) showed that virtual reality implementations could be a significant tool for individuals with different disabilities. This condition could also create equal opportunities in learning environments. In this manner, the feeling of being present in the related environment caused by VR environments could be claimed as very effective. Participants emphasized that VR environments could meet the need of excursion and this could be attributed to the fact that they had a similar feelings with VR environments. They also emphasized that the provided contents could support individuals' concrete learning experiences. Similarly, Youngblut (1998) stated that virtual reality implementations facilitated learning and supported education. This result is attributed to the fact that participants engaged in the process and regarded themselves as a part of the environments. However, during preparation of VR environments, the possibility of use of these technologies in the long run and more effectivity of the contents which are more close to reality are among the study results. In this manner, Hussein and Nätterdal (2015) stated that VR environments could draw individuals away from the real world.

Participants were requested to make a comparison between the content provided in classrooms, i.e. image and video, and the contents provided in VR environments. In this context, it was emphasized that VR environments could create more memorable learning environments compared to other mentioned environments. In the creation of this result, it is important that participants found themselves a role in the provided content. Additionally, it was frequently stated that the provided contents could facilitate learning depending on VR environments increased permanency. Furthermore, it was though that participants found these environments more enjoyable and interesting since they saw the contents in VR environments at the first time. Additionally, some of the VR environments were regarded as motivation increasing factor because they provided opportunity for individual learning. Başaran (2010) emphasized that one of the main advantages of virtual reality implementations was individual oriented control program. With this perspective, the result is determined as virtual reality implementations affect individual learning in positive manners.

As a result, participants liked the content that was provided in the scope of this study. In the creation of liking level, the feeling of being present in the environment caused by the provided content was important. Additionally, it was thought that the content provided in VR environments was exciting and this condition increased participants' desire to go and be present in the real location. Besides, realistic contents were considered as another condition that affected their liking levels. Similarly, Hussein and Nätterdal (2015) stated that VR technologies based environments were more effective in conditions that included interactive environmental environments, compared to traditional environments. It was observed that use of VR environments in history courses and especially use of these technologies in showing historically important events (i.e. wars, treaties, negotiations, and discussions etc.) was regarded as useful. For the creation of this condition, it was thought that participants' desire to observe important events better and to experience the feeling of being present in that location were effective. Additionally, another result is that historical excursions can be organized with VR technologies. It was though that participants made a choice like this due to obtain more information and learn more about the historical places that they could only reach with 2 dimensional ways and could not find an opportunity to go. Hence, it was though that they could learn about the places more permanently since they felt as if they were present in the related environment by themselves. Similarly, Sürücü (2017) stated that virtual reality environments provided quicker learning opportunities. Additionally, virtual reality environments gave students opportunities to make their own experiences so that students learnt more permanently (Sürücü, 2017).

In general, it was observed that VR based learning implementations reached a high level of liking. Similarly, it was determined that participants considered use of this technology in course activities as useful. Especially, the reality feelings and the feeling of being present in the related environment caused by virtual reality implementations were considered the factors that influenced participants and increased their motivations toward the course. Additionally, virtual reality implementations were considered as they had a big potential in creation an environment that individuals with disabilities or had some kinds of inadequacies (i.e. financial and time etc.) could use in learning processes.

\subsection{Suggestions}

1. The current study was conducted with undergraduate students. It can be applied to students in different levels as necessary conditions are met.

2. Ready contents were benefited in the scope of this study. In other studies to be conducted, environments can be designed in accordance with the current conditions.

\section{References}

Adesote, S.A. and O.R. Fatoki, 2013. The role of ICT in the teaching and learning of history in the 21 st century. Educational Research and Reviews, 8(21): 2155-2 159. View at Google Scholar | View at Publisher 
Allison, J., 2008. History educators and the challenge of immersive pasts: A critical review of virtual reality 'tools' and history pedagogy. Learning, Media and Technology, 33(4): 343-352. View at Google Scholar | View at Publisher

Azuma, R., 1997. A survey of augmented reality. Teleoperators and Virtual Environments, 6(4): 355-385. View at Google Scholar

Başaran, F., 2010. Teacher candidates' views on the use of virtual reality in education (Sakarya University BÖTE example). Master's Thesis, Sakarya University Institute of Social Sciences, Sakarya.

Bilgin, N., 1999. Content analysis. Methods and Practical Studies in Social Psychology, Ege University, Faculty of Letters, Izmir: $127-152$.

Büyüköztürk, Ş., E.K. Çakmak, Ö.E. Akgün, Ş. Karadeniz and Demirel, 2010. Scientific research methods. 5th Edn., Ankara: Pegem Academ.

Carrozzino, M. and M. Bergamasco, 2010. Beyond virtual museums: Experiencing immersive virtual reality in real museums. Journal of Cultural Heritage, $11(4):$ 452-458. View at Google Scholar $\mid$ View at Publisher

Çavaş, B., P.H. Çavaş and B.T. Can, 2004. Virtual reality in education. Turkish Online Journal of Educational Technology, 3(4).

Ertürk, S., 1972. Curriculum development in education. Ankara: Yelkentepe Publications.

Fer, S., 2011. Learning teaching theories and approaches. Ankara: Anı Yayıncılık.

Hussein, M. and C. Nätterdal, 2015. The benefits of virtual reality in education: A comparison study. (Bachelor of Science Thesis in Software Engineering and Management Student essay), Chlamers University of Technology, University of Gothenburg, Göteborg, Sweden. Retrieved from: https://gupea.ub.gu.se/bitstream/2077/39977/1/gupea_2077_39977_1.pdf.

McLellan, H., 1996. Virtual realities, Editör: Jonassen, D., Handbook of research for educational communications and technology. Boston: Kluwer-Nijhoff Publishing, pp: 457-487.

Neamtu, C., R. Comes, R. Matescu, R. Ghinea and F. Daniel, 2012. Using virtual reality to teach history. In The 7th Internional Conference on Virtual Learning. pp: 303-311.

Nooriafshar, M., R. Williams and T. Maraseni, 2004. The use of virtual reality in education. American Society of Business and Behavioral Sciences (ASBBS) 2004 Seventh Annual International Conference, 6-8 Aug 2004, Cairns, Australia.

Pantelidis, V.S., 2010. Reasons to use virtual reality in education and training courses and a model to determine when to use virtual reality. Themes in Science and Technology Education, 2(1-2): 59-70. View at Google Scholar

Rheingold, H., 1991. Virtual reality: Exploring the brave new technologies. Simon \& Schuster Adult Publishing Group.

Schweizer, H., 2014. Smart glasses: Technology and applications. Student Report.

Stradling, R., 2003. 20th century European history should be taught how (Cev.ayf Ünal). Istanbul: Turkey Economic and Social History Foundation Publications.

Sürücü, O., 2017. The use of virtual reality to protect cultural heritage. Salih Bozok Villa Doctoral Dissertation, Selcuk University Institute of Science.

Youngblut, C., 1998. Educational uses of virtual reality technology (No. IDA-D-2 128). Institute For Defense Analyses Alexandria Va. pp: 1111. Retrieved from: http://www.dtic.mil/dtic/tr/fulltext/u2/a339438.pdf. 